\title{
Co-circulation of genotypes IA and IB of hepatitis A virus in Northeast Brazil
}

L.M. Villar ${ }^{1}$, L.M. Morais ${ }^{1}$, R. Aloise' ${ }^{1}$ M.M.M. Melo ${ }^{2}$, I.A. Calado ${ }^{2}$, E. Lampe ${ }^{1}$ and A.M.C. Gaspar ${ }^{1}$

\author{
${ }^{1}$ Departamento de Virologia, Instituto O swaldo Cruz, FIOCRUZ, \\ Rio de Janeiro, RJ, Brasil \\ ${ }^{2}$ Laboratório Central de Saúde Pública do Estado de Pernambuco, \\ Recife, PE, Brasil
}

\section{Correspondence \\ L.M. Villar \\ Departamento de Virologia, FIOCRUZ \\ Av. Brasil, 4365 \\ 21045-900 Rio de Janeiro, RJ \\ Brasil \\ Fax: + 55-21-2270-6397 \\ E-mail: Ivillar@ioc.fiocruz.br}

Research supported by CNPq, CAPES, FACEP, and CGLAB.

Received June 28, 2005 Accepted March 20, 2006

\section{Abstract}

The Northeast region is the location of most cases of acute hepatitis A virus (HAV) in Brazil. In the present study, the genotypes of HAV strains from Pernambuco State, one of most populous states in the Northeast region, were characterized. Blood samples positive for antiHAV IgM from 145 individuals (mean age $=29.1$ years), collected during 2002 and 2003, were submitted to nested RT-PCR for amplification of the 5'non-translated region (5'NTR) and VP1/2A regions of the HAV genome. The VP1/2A and 5'NTR regions were amplified in 39 and $21 \%$ of the samples, respectively. Nucleotide sequencing was carried out in $46 \%$ of $\mathrm{VP} 1 / 2 \mathrm{~A}$ and in $53 \%$ of 5 'NTR isolates. The identity in nucleotide sequence of the VP1/2A region ranged from 93.6 to $100.0 \%$. Phylogenetic analysis of the VP1/2A sequences showed that $65 \%$ belong to sub-genotype IA and $35 \%$ to sub-genotype IB. Co-circulation of both sub-genotypes was observed in the two years studied. Distinct clusters of highly related sequences were observed in both sub-genotypes, suggesting endemic circulation of HAV strains in this area. In the 5'NTR isolates, 92.7-99.2\% identity was observed and two isolates presented one deletion at position 413 . Phylogenetic analysis showed that genotype IA strains cluster in the tree in the same way as genotype IB strains, but one IIIA isolate from Spain clusters with genotype IB strains. These results do not allow us to state that 5'NTR could be used to genotype HAV sequences. This is the first report of co-circulation of sub-genotypes IA and IB in this region, providing additional information about the molecular epidemiology of HAV strains in Brazil.

\section{Introduction}

Hepatitis A virus (HAV) is an RNA virus belonging to the hepatovirus genus in the Picornaviridae family (1). HAV isolates from different parts of the world have been classified into six genotypes based on a 168-nucleo-

\section{Key words}

- Hepatitis A virus

- Molecular epidemiology

- Sub-genotype IA

- Sub-genotype IB tide sequence at the virion protein 1 and $2 \mathrm{~A}$ genes (VP1/2A junction) (2,3). The most frequent human genotype is genotype I (more than $80 \%$ ), which has been divided into two sub-genotypes: IA and IB.

HAV is usually transmitted by the fecaloral route through contaminated water and 
food or by person-to-person contact in schools and in day-care centers (4-7). The epidemiology of HAV infection in Brazil is characterized by a heterogeneous pattern, with low endemicity observed in the South and Southeast regions, with an anti-HAV prevalence rate of $55.7 \%$, whereas the highest anti-HAV rates, 92.8 and $76.5 \%$, are observed in the North and Northeast regions, respectively (8). This situation demonstrates the importance of carrying out epidemiological studies in the North and Northeast regions of Brazil.

In previous studies by our group on the molecular epidemiology of HAV in Brazil $(7,9,10)$, sub-genotypes IA and IB were detected among acute HAV cases and among HCV-co-infected patients in the Rio de Janeiro population, whereas in other 8 states of Brazil only sub-genotype IA was found. More detailed studies are necessary to determine the real distribution of HAV genotypes in our country, and for this reason we presently evaluated the circulation of HAV subgenotypes in Pernambuco State, one of the most populous states of the Northeast region.

Recently, it was demonstrated that the central part of the 5' non-translated region (5'NTR) of HAV might be correlated with the severity of HAV infection $(11,12)$. In order to study the variability of the nucleotide sequence in both regions of the HAV genome and to identify the genotypes circulating in the Northeast region of Brazil, direct nucleotide sequencing and phylogenetic analysis were performed on HAV strains obtained from patients reported to the Public Health Laboratory of Pernambuco State from October 2002 to September 2003.

\section{Patients, Material, and Methods}

\section{Serum samples}

A total of 145 anti-HAV IgM cases of hepatitis from the Central Public Health Lab- oratory of Pernambuco State (C.P.H.L.P.S.) were detected during 2002-2003. Samples were collected by venipuncture, transported in an ice box to the laboratory and kept at $-20^{\circ} \mathrm{C}$ until assayed. Pernambuco is a mixed urban and rural area of Brazil that receives a large number of travelers and visitors. It is located in the northeast region of Brazil and has approximately 8,000,000 inhabitants distributed among 185 counties.

\section{Serological tests}

Anti-HAV IgM antibodies were detected in serum samples with commercially available ELISA kits (Organon Teknika, Boxtel, The Netherlands) according to manufacturer instructions. To exclude other etiologies of hepatitis, serum samples were also tested for hepatitis B surface antigen ( $\mathrm{HBsAg}$ ) and for IgM antibodies directed against the HBV core protein (anti-HBc IgM) using Hepanostika HBsAg Uni-form II and HBc IgM kits (Organon Teknika), respectively. The presence of anti-HCV antibodies was tested by enzyme immunoassay (UBI HCV EIA 4.0 kit, Organon).

\section{HAV RNA amplification and sequencing}

Viral RNA was extracted from $100 \mu \mathrm{L}$ of serum by a modified version of the TRIzol ${ }^{\circledR}$ method (Life Technologies, Rockville, MD, USA) as described previously (7). Reverse transcription was carried out at $37^{\circ} \mathrm{C}$ for $1 \mathrm{~h}$ with a random primer (Life Technologies) and using Moloney murine leukemia virus reverse transcriptase (Life Technologies). One half of the cDNA was used in a PCR assay that amplified parts of VP1/2A junction. After 4-min denaturation at $94^{\circ} \mathrm{C}$, DNA was amplified for 30 cycles at $94^{\circ} \mathrm{C}$ for $30 \mathrm{~s}$, $40^{\circ} \mathrm{C}$ for $30 \mathrm{~s}, 72^{\circ} \mathrm{C}$ for $1 \mathrm{~min}$, and an additional $7 \mathrm{~min}$ at $72^{\circ} \mathrm{C}$ in the last cycle, in a final volume of $50 \mu \mathrm{L}$ using Taq polymerase (Life Technologies). The primers used in this first round of PCR were based on previ- 
ously described sense +2897 and antisense -3288 primers (13), degenerated as follows to be able to amplify all HAV genotypes ('universal primers'): 5' CTATTCAGATTG CAAATTAYAAT 3' (sense) and 5' AAYTT CATYATTTCATGCTCCT 3' (antisense), where $\mathrm{Y}$ represents $\mathrm{C}$ or T. Nested PCR was carried out with $1 \mu \mathrm{L}$ of the first round PCR product for 30 cycles under the same conditions (except that the annealing temperature was increased to $\left.48^{\circ} \mathrm{C}\right)$. Internal primers were +2949 and -3192 (2) modified as follows: 5' TATTTGTCTGTYACAGAACAATCAG3' (sense) and 5' AGGRGGTGGAAGYACTT CATTTGA 3' (antisense), where R represents $\mathrm{A}$ or $\mathrm{G}$.

For nested RT-PCR for 5'NTR, we used a protocol described by Pina et al. (14). A $10-\mu \mathrm{L}$ sample of cDNA was used for amplification that was carried out in a $50-\mu \mathrm{L}$ reaction mixture with 25 pmol of each primer: HAV1 (TTGGAACGTCACCTTGCAGTG) and HAV2 (CTGAGTACCTCAGAGG CAAAC) and Taq polymerase (Life Technologies). The first denaturation cycle was carried out for $3 \mathrm{~min}$ at $95^{\circ} \mathrm{C}$, followed by 30 cycles of denaturation at $95^{\circ} \mathrm{C}$ for $60 \mathrm{~s}$, annealing at $55^{\circ} \mathrm{C}$ for $60 \mathrm{~s}$, and extension at $72^{\circ} \mathrm{C}$ for $60 \mathrm{~s}$. The final extension step was done at $72^{\circ} \mathrm{C}$ for $5 \mathrm{~min}$. Then, $1 \mu \mathrm{L}(1 / 50)$ of the reaction mixture was added to a new batch of a 50- $\mu \mathrm{L}$ PCR mixture containing 25 pmol of each nested primer: neHAV1 (ATCTCTTTGATCTTCCACAAG) and neHAV2 (GAACAGTCCAGCTGTCAA TGG) for a new PCR amplification cycle following the same procedure.

Amplicons of expected size (244 bp for VP1/2A and 290 bp for 5'NTR) were purified using the QIAquick Gel extraction kit (Qiagen, Valencia, Spain) according to manufacturer instructions. The direct nucleotide sequencing reaction was carried out in both directions with the Big Dye Terminator kit (Applied Biosystems, Foster City, CA, USA) and an automatic DNA sequencer model ABI Prism 310 (Applied Biosystems). The sequences reported in this paper have been deposited in the GenBank sequence database under the following accession numbers: AY995696 to AY995711 for the 5'NTR sequences and AY994302-AY994310; DQ002551-DQ002567 for the VP1/2A sequences.

To avoid cross-contamination between samples, standard precautions were applied in all manipulations. Separate areas were used for reagents, for samples and for manipulation of the amplified products. All samples were analyzed twice in independent experiments and samples from healthy persons were always used as negative control for each reaction.

\section{Sequence analysis}

Algorithms within the GCG package (Wisconsin Sequence Analysis Package; Genetic Computer Group, Madison, WI, USA, version 10.1) were used for alignment of nucleotide and deduced amino acid sequences. Initial multiple alignments were performed with the PILEUP program; further adjustments of the alignments were performed manually using visual correction based on sequence comparison generated with the PRETTY program in GCG. Phylogenetic trees were created by the neighborjoining method and the Kimura two-parameter model (15) using the computer software MEGA 2.1 (16) and their reliability was assessed by bootstrap resampling (1000 pseudo-replicates).

\section{Statistical analysis}

Data are reported as means \pm SD. Frequencies were compared using the $\chi^{2}$ test for independence with Yates's correction, with the level of significance set at $\mathrm{P}<0.05$ (twotailed). All statistical analyses were carried out using the Graph Pad Instat 1998 software, version 3.01 for Windows 95 (Graph Pad Software, San Diego, CA, USA). 


\section{Results}

Of the 145 anti-HAV IgM samples collected from patients (sporadic cases) who were referred to C.P.H.L.P.S., none was positive for anti-HBc IgM, HBsAg or anti-HCV. Of 145 acute hepatitis A cases, $51.03 \%$ were male, the mean age was 29.1 years (range, 0 58 years), and $45 \%$ were older than 10 years. Fifty-six percent of the individuals reported signs and symptoms of acute hepatitis such as jaundice, nausea, and dark urine and 18\% were asymptomatic. The VP1/2A sequence was amplified in $39 \%$ samples whereas the 5 'NTR region was detected in $21 \%$. In addition, $17 \%$ of the individuals were positive for both regions. HAV positivity did not correlate with age, sex, city of residence, or presence of symptoms (Table 1).

For nucleotide sequencing, only positive nested RT-PCR samples presenting sufficient DNA quantities ( $20 \mathrm{ng} / \mu \mathrm{L})$ were used; thus, $46 \%$ of the VP1/2A regions and $53 \%$ of the 5'NTR regions were sequenced. Comparison of 218 nucleotide sequences from the VP1/2A region of Pernambuco HAV isolates with different reference strains showed that all sequences belonged to genotype I, 17 of them as sub-genotype IA and 9 as sub-genotype IB. The identity in nucleotide sequence ranged from 93.6 to $100.0 \%$ among genotype IA strains and from 95.0 to $100 \%$ among genotype IB isolates. HAV sequences from the VP1/2A region studied are displayed in the phylogenetic tree constructed by the neighbor-joining method (Figure 1) that includes reference sequences from genotypes IA, IB, IIIA, and IIB. Co-circulation of sub-genotypes IA and IB was observed in the two years of the study (2002 to 2003), but in the last year most of the sequences belonged to sub-genotype IB (6/ 11). Separate clusters of related HAV strains can be observed among isolates from Pernambuco of both genotypes.

Analysis of 248 nucleotides of the 290bp nested PCR amplicons from the 5'NTR sequences showed $92.7-99.2 \%$ identity among them. None of these sequences were identical to each other; however, two isolates (PE-19920 and PE-19921) shared one deletion at position 413 . These samples be-

Table 1. Characteristics and risk factors for hepatitis A virus infection in the population studied.

\begin{tabular}{|c|c|c|c|c|}
\hline \multirow[t]{2}{*}{ Characteristic } & \multicolumn{2}{|c|}{ VP1/2A region } & \multicolumn{2}{|c|}{$5^{\prime} N T R$ region } \\
\hline & $\begin{array}{c}\text { Positive } \\
\mathrm{N}=56(38.62 \%)\end{array}$ & $\begin{array}{c}\text { Negative } \\
\mathrm{N}=89(61.37 \%)\end{array}$ & $\begin{array}{c}\text { Positive } \\
N=30(20.68 \%)\end{array}$ & $\begin{array}{c}\text { Negative } \\
\mathrm{N}=115(79.31 \%)\end{array}$ \\
\hline \multicolumn{5}{|l|}{ Age (years) ${ }^{a}$} \\
\hline$\leq 10$ & $39(45 \%)$ & $48(55 \%)$ & $17(20 \%)$ & $70(80 \%)$ \\
\hline$>10$ & $14(31 \%)$ & $31(69 \%)$ & $8(18 \%)$ & $37(82 \%)$ \\
\hline \multicolumn{5}{|l|}{ Sex } \\
\hline Male & $29(39 \%)$ & $45(61 \%)$ & $18(24 \%)$ & $56(76 \%)$ \\
\hline Female & $27(38 \%)$ & $44(62 \%)$ & $12(17 \%)$ & $59(83 \%)$ \\
\hline \multicolumn{5}{|l|}{ City of residence } \\
\hline Recife & $17(47 \%)$ & $19(53 \%)$ & $7(19 \%)$ & $29(81 \%)$ \\
\hline Other counties & $39(36 \%)$ & $70(64 \%)$ & $23(21 \%)$ & $86(79 \%)$ \\
\hline \multicolumn{5}{|c|}{ Presence of symptoms } \\
\hline Yes & $50(42 \%)$ & $69(58 \%)$ & $26(22 \%)$ & $93(78 \%)$ \\
\hline No & $6(23 \%)$ & $20(77 \%)$ & $4(15 \%)$ & $22(85 \%)$ \\
\hline
\end{tabular}

Risk factors were represented by age, city of residence and presence of symptoms. Data are reported as

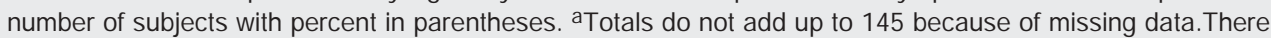
were no statistical differences between positive and negative subjects tested for VP 1/2A or 5'NTR ( $\chi^{2}$ test). 
longed to genotype IA as determined by sequence analysis in the VP1/2A region and were isolated from two patients living in different counties during the same month (July 2003). Phylogenetic analysis was performed among 5'NTR sequences and sequences from genotype IA were found to cluster in the tree in the same way as genotype IB strains (Figure 2). However, one sample identical to one previously isolated in Spain (AF386827) belongs to genotype IIIA and clusters together with other strains from genotype IB. Furthermore, not all of 5'NTR sequences of this study were amplified in the VP1/2A region, and therefore the genotype of these samples was not determined. These results do not allow us to state that 5'NTR can be used to genotype HAV sequences.

A comparison of the predicted amino acid sequences of the VP1/2A region from Pernambuco, of two isolates representative of genotypes IA and IB in the world and two more sequences from South America is shown in Figure 3. Identity in amino acid sequence ranged from 93.1 to $100 \%$ among

Figure 1. Phylogenetic tree analysis of the VP1-2A region in hepatitis $A$ virus (HAV) isolates from Pernambuco (PE). A 218-bp segment of the HAV VP1/2A junction was analyzed using the two-parameter model of Kimura. The numbers on the branches show bootstrap percentages obtained after 1000 replicates of bootstrapping sampling. The length of bars shows the distances. The numbers in parentheses show the month and year of strain isolation. Genotype and subgenotype are indicated for each branch. Reference sequences from Genbank included: genotype IA strains (HAS 15 x15464), genotype IB strains (HM175 m14707), genotype IIB strain (SLF 88 ay644670), genotype III strain (NOR21 aj299464), BA303 (ay 323017), BA351 (ay 323018), RJ 104 (ay 323022), RJ 178 (ay 323023), MA367 (ay 323036), MA347 (ay 323039) MA378 (ay 323037), BA251 (ay 323033), RJ 12 (ay 323034), MA374 (ay 323040), RN243 (ay 323005), MG 287 (ay 323007), RJ 193 (af 410388), HAP009 (af 538723), RJPMC1 (af410386), HAP 108 (DQ198361), Nor13 (af 050234), HAP231 (DQ198360), RJ NSG2 (af 410383), HAP 279 (DQ 198362), HAP 343 (DQ198363), RJ 004 (af410380), RJ 005 (af 410381), RJ 049 (ay 322851), HAP 300 (af 538727).

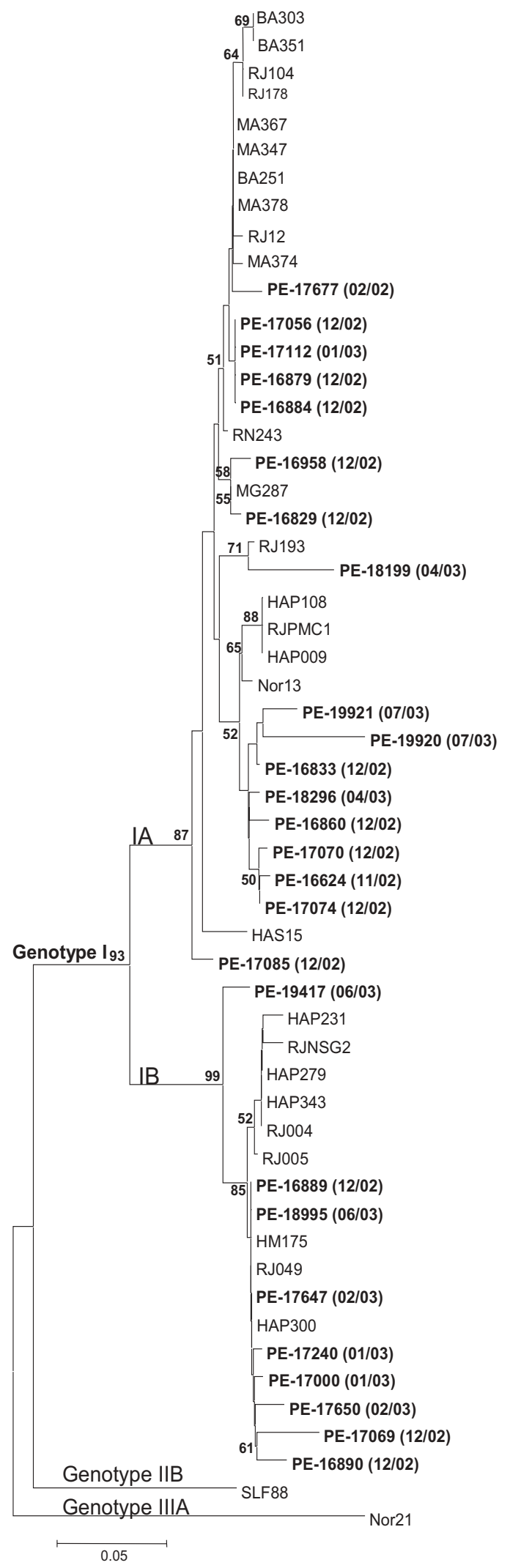




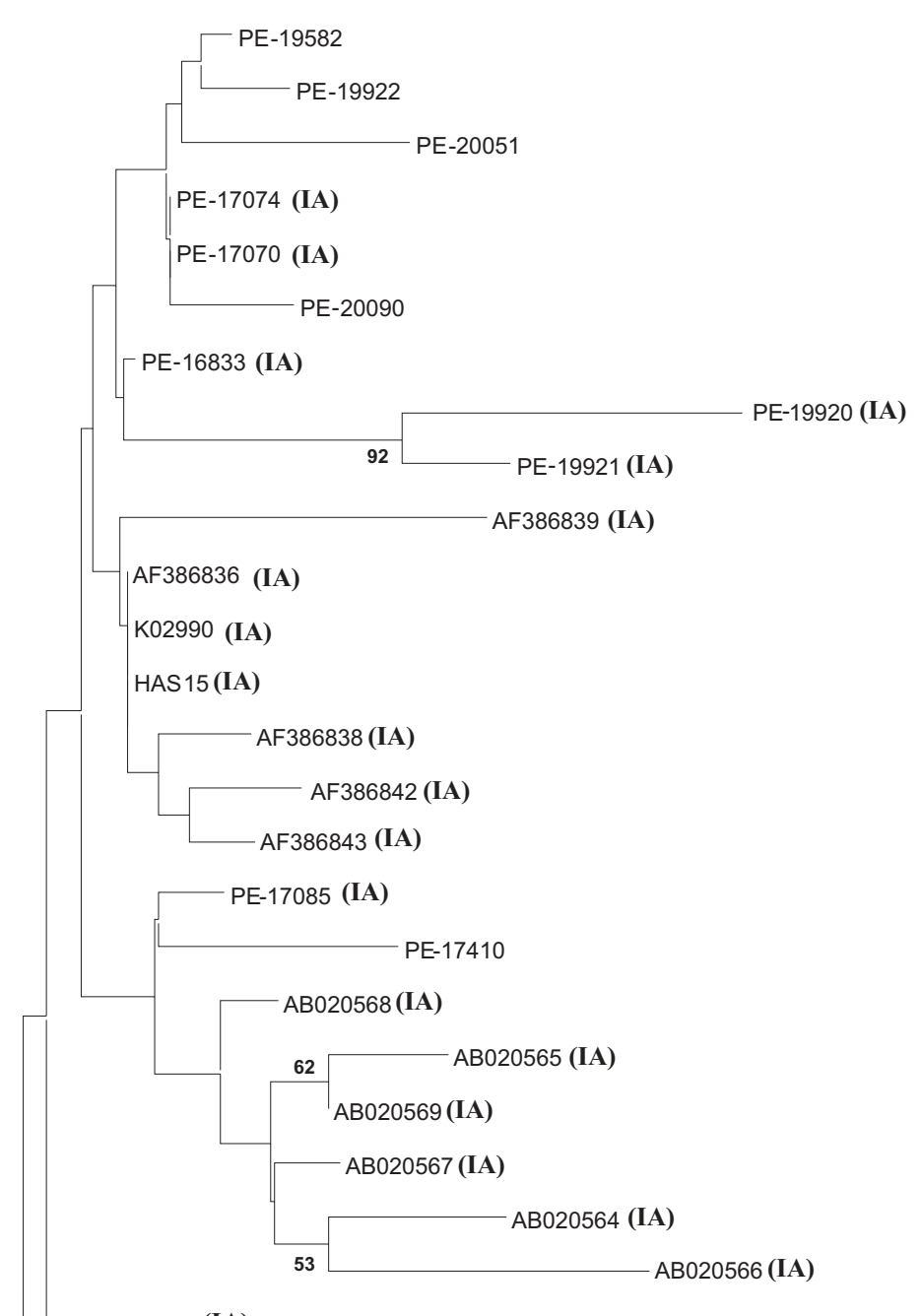

PE-17056 (IA)

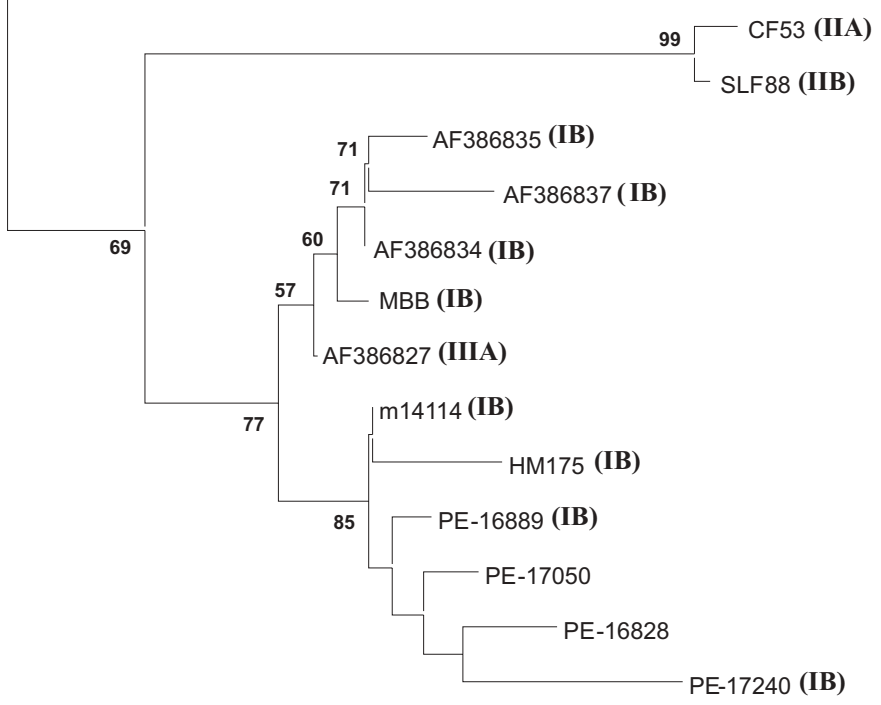

IA strains and from 90.3 to $100 \%$ among IB strains. In sub-genotype IB, mutation in nucleotide sequence produces proportionally more changes than in IA strains, where most substitutions are in the third position. Therefore, 13 sub-genotype IA strains showed identical amino acid sequences whereas only three IB sub-genotype isolates showed the same amino acid sequence. However, the difference in the number of amino acid changes among isolates from two subgenotypes was not statistically significant ( $\mathrm{P}$ $=0.82 ; \chi^{2}$ for independence $=0.05$ ).

\section{Discussion}

Brazil exhibits a very heterogeneous pattern of endemicity for HAV infection, varying according to geographical region and socioeconomic groups. In the past, Brazil was considered to be an area of high endemicity with nearly all people being infected in early childhood (4). However, recent epidemiological studies have demonstrated that, except for the North region, there has been a shift from high to medium endemicity of HAV infection, which may result in more clinical cases as the consequence of an increased number of individuals susceptible to infection, mainly adolescents and adults (5-

Figure 2. Phylogenetic tree analysis of the 5 'NTR in hepatitis $A$ virus (HAV) isolates from Pernambuco (PE). A 290-bp segment of the HAV 5'NTR was analyzed using the two-parameter model of Kimura (see Ref. 15). The numbers on the branches show bootstrap percentages obtained after 1000 replicates of bootstrapping sampling. The length of bars shows distances. The numbers in parentheses indicate the genotype of this isolate according to the VP1/2A region. Note that not all of the 5'NTR sequences were amplified in the VP1/2A region. Isolate AF 386827, displayed in the box, belongs to genotype IIIA and clusters with IB strains. Reference sequences from Genbank included genotype IA strains (HAS15 x15464), genotype IB strains (HM175 m14707) (MBB m20273), genotype IIB strain (SLF88 ay644670), genotype IIA strain (CF53 aj299464), and other sequences from acute cases of hepatitis A virus that appear as the Genbank number. 
$7,17,18)$. In the present study, we observed that $45 \%$ of acute cases were identified among individuals older than 10 years, a situation normally found in regions of intermediate endemicity, confirming a change from high to medium endemicity in this region. Furthermore, the prevalence of HAV infection increased proportionally to age in the other $55 \%$ of individuals, since $16 \%$ of the individuals aged less than 5 years and $39 \%$ of the individuals aged 5 to 10 years were acutely infected. These findings agree with the results of several seroepidemiological studies that have shown a marked change in the epidemiological pattern of hepatitis A in many parts of the world due to improvements in living standards (19-21).

Phylogenetic analysis of the nucleotide sequence of the VP1/2A region of the HAV genome classified all isolates as genotype I, confirming former epidemiological data demonstrating that this is the main genotype circulating in Brazil $(7,10,22)$ as well the most widespread genotype in the world $(2,23,24)$. Additionally, we identified the simultaneous presence of sub-genotypes IA and IB in 65 and $35 \%$ of cases of HAV infection, respectively. The presence of both sub-genotypes has not been detected previously in the Northeastern region. de Paula et al. (10) observed that all HAV sequences belonged to sub-genotype $1 \mathrm{~A}$ in other States of the Northeastern region. Only in the Southeastern region was the co-circulation of subgenotype 1A and 1B detected before $(7,22)$.

HAV isolates from Pernambuco State formed distinct clusters of highly related sequences and this is consistent with previ-
VP1

257

HM1 75 ( IB)

HAP 300 (IB)

$\mathrm{PE}-16889$

$\mathrm{PE}-16890$

$\mathrm{PE}-17000$

$\mathrm{PE}-17069$

$\mathrm{PE}-17240$

$\mathrm{PE}-17647$

$\mathrm{PE}-17650$

$\mathrm{PE}-18995$

$\mathrm{PE}-19417$

HAS 15 (IA)

HAPOO 9 (IA)

$\mathrm{PE}-16624$

$\mathrm{PE}-16829$

$\mathrm{PE}-16833$

$\mathrm{PE}-16860$

$\mathrm{PE}-16879$

$\mathrm{PE}-16884$

$\mathrm{PE}-16958$

$\mathrm{PE}-17056$

$\mathrm{PE}-17070$

$\mathrm{PE}-17074$

$\mathrm{PE}-17085$

PE-17112

PE-17677

$\mathrm{PE}-18199$

$\mathrm{PE}-18296$

$\mathrm{PE}-19920$

PE-19921
3001

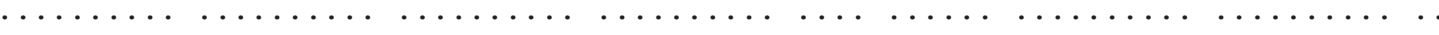

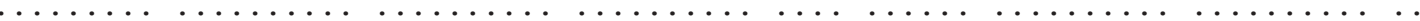

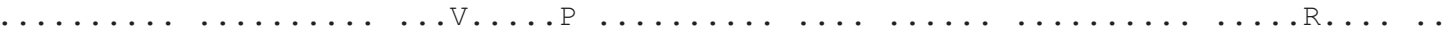

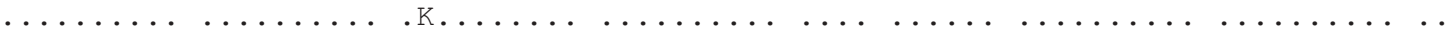

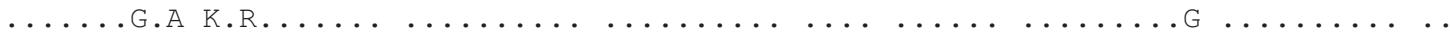

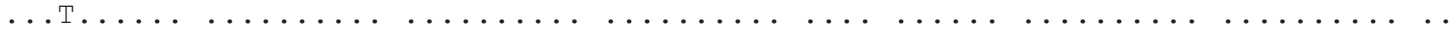

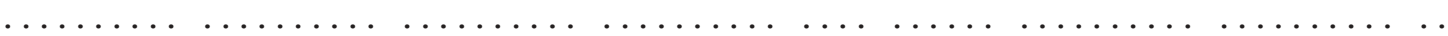

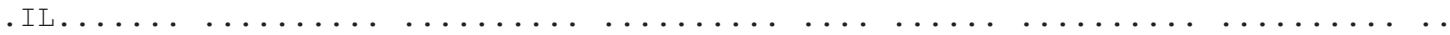

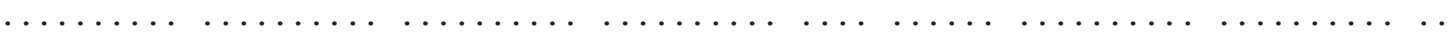

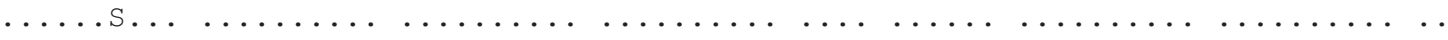

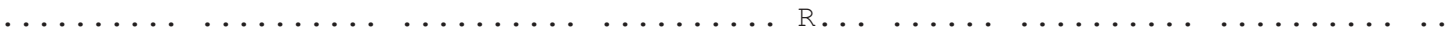

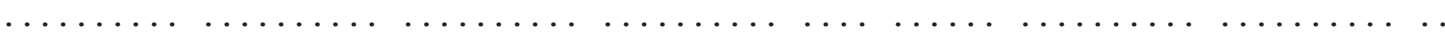

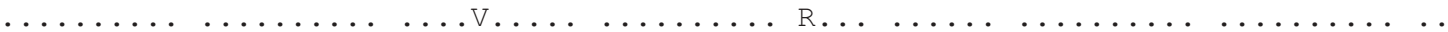

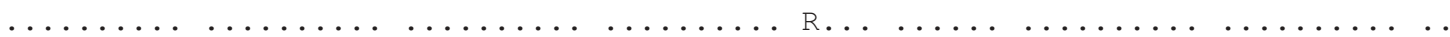

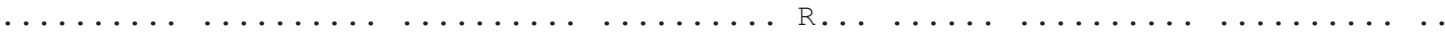

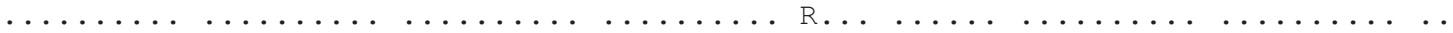

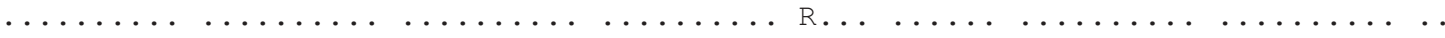

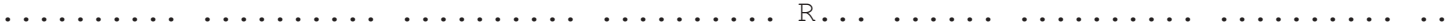

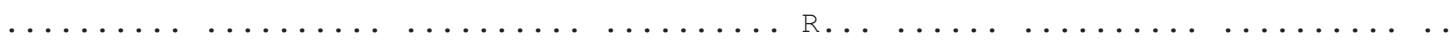

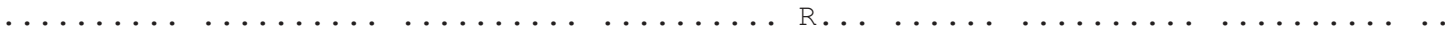

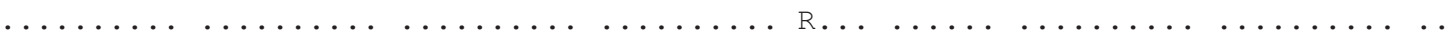

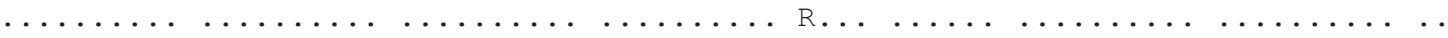

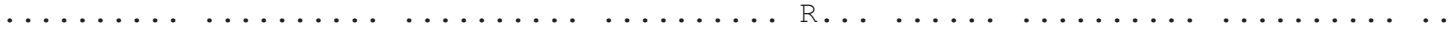

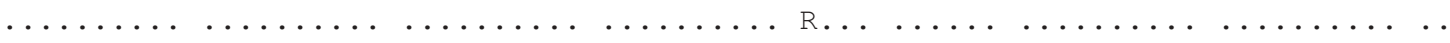

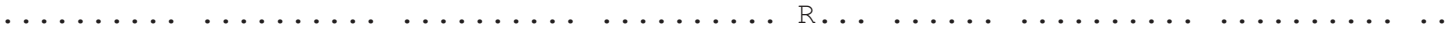

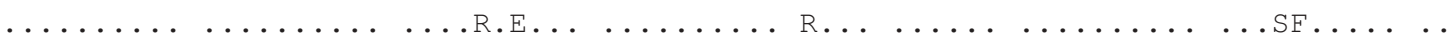

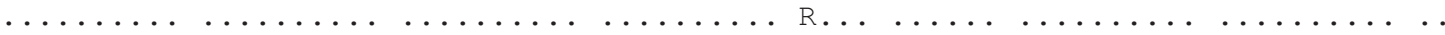

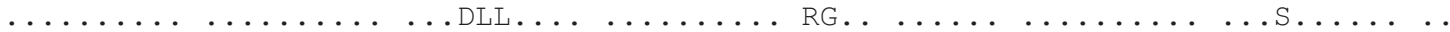

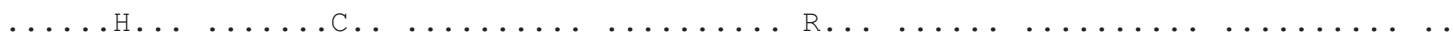

Figure 3. Comparison of the predicted amino acid sequence of the VP1/2A junction of the hepatitis A virus strains studied. 
ous speculation about low rates of accumulating mutations among HAV strains and the development of specific ecological niches (23). Thus, these data suggest that there is a circulation of endemic HAV strains in this region, as demonstrated in other regions of Brazil $(7,10)$. Moreover, the presence of the same strains sharing the same nucleotide sequence might indicate the presence of unidentified epidemic foci, since these isolates were identified in cases that occurred during a short period of time (most of them in December 2002).

The Pernambuco genotype IB isolates differ in predicted amino acid sequences amongst themselves as compared to genotype IA strains. However, the difference in the number of amino acid changes is not significant. Furthermore no one has shown that these differences alter infectivity. Fujiwara et al. (25) demonstrated that disease severity was not associated with the nucleotide sequence of the HAV genotype-determining region.

In the 5'NTR, few nucleotide substitutions were observed among our isolates when compared to VP1/2A sequences, confirming the conserved nature of this region. However, the amplification of 5'NTR was less efficient than one would have expected in this conserved region. Phylogenetic analysis based on the 5'NTR region produced an apparent separation between IA and IB subgenotypes. However, taking into consideration the misclassification of the IIIA strain into the IB group, we may assume that the 5'NTR region, probably due to the highly conserved nature of the sequences, does not contain sub-genotype-specific motifs which faithfully reflect the diversity of the VP1/2A region and therefore is not appropriate for use for sub-genomic classification.
Interestingly, two isolates shared one deletion at position 413 in the 5'NTR region. Recent studies have demonstrated that alterations in the central part of the 5'NTR region of HAV could result in significant functional changes of the virus. Brown et al. (26) showed that deletion of base 447 slightly decreased translation, while deletion of base 533 almost completely abolished it. Furthermore, they demonstrated that $\mathrm{G}$ to $\mathrm{U}$ mutation at nucleotide 646 localized in the terminal part of 5'NTR could alter the secondary structure of the HAV genome. Schultz et al. (27) reported that mutations within the 5'NTR region of cell-adapted HAV enhance capindependent translation directed by HAV IRES in a cell type-specific fashion. The deletion found in the present study had never been identified in HAV isolates and therefore we could not predict an alteration in secondary structure or HAV translation. Fujiwara et al. (12) reported a possible association between the severity of type A hepatitis and nucleotide substitutions in the middle part of 5'NTR. However, in our study the presence or absence of symptoms was not associated with the mutations in this part of genome.

The sequence analysis of HAV strains from the Northeast region of Brazil indicated that they are closely related, suggesting an endemic circulation of the same HAV strains in this region. The high incidence of acute cases observed among adolescents and young adults, in whom HAV infection usually causes a more severe infection, indicates the necessity of reviewing the strategy for hepatitis A vaccination. This is the first report of co-circulation of sub-genotypes IA and IB in this region, providing additional information about the molecular epidemiology of HAV in Brazil. 


\section{References}

1. Minor P. Classification and nomenclature of viruses (Arch. Virol. Suppl. 2). In: Francki RIB, Fauquet CM, Knudson DL, Brown $F$ (Editors), P icornaviridae. Wien: Springer-Verlag; 1991. p 320-326.

2. Robertson $B H$, J ansen RW, Khanna B, Totsuka A, Nainan OV, Siegl $G$, et al. Genetic relatedness of hepatitis A virus strains recovered from different geographical regions. J Gen Virol 1992; 73 (Pt 6): 1365-1377.

3. Lu L, Ching KZ, de Paula VS, Nakano T, Siegl G, Weitz M, et al. Characterization of the complete genomic sequence of genotype II hepatitis A virus (CF53/Berne isolate). J Gen Virol 2004; 85: 29432952.

4. Vitral CL, Yoshida CFT, Lemos ERS, Teixeira CS, Gaspar AMC. Age-specific prevalence of antibodies to hepatitis $A$ in children and adolescents from Rio de J aneiro, Brazil, 1978 and 1995. Relationship of prevalence to environmental factors. Mem Inst Oswaldo Cruz 1998; 93: 1-5.

5. Villar LM, da Costa MCE, de Paula VS, Gaspar AMC. Hepatitis A outbreak in a public school in Rio de Janeiro, Brazil. Mem Inst Oswaldo Cruz 2002; 97: 301-305.

6. Santos DC, Souto FJ, Santos DR, Vitral CL, Gaspar AM. Seroepidemiological markers of enterically transmitted viral hepatitis $\mathrm{A}$ and $\mathrm{E}$ in individuals living in a community located in the North Area of Rio de J aneiro, RJ, Brazil. Mem Inst Oswaldo Cruz 2002; 97: 637-640.

7. Villar LM, Lampe E, Meyer A, Gaspar AM. Genetic variability of hepatitis $A$ virus isolates in Rio de Janeiro: implications for the vaccination of school children. Braz J Med Biol Res 2004; 37: 17791787.

8. Clemens SA, da Fonseca J C, Azevedo T, Cavalcanti A, Silveira TR, Castilho MC, et al. Hepatitis $A$ and hepatitis $B$ seroprevalence in 4 centers in Brazil. Rev Soc Bras Med Trop 2000; 33: 1-10.

9. Devalle S, de Paula VS, de Oliveira J M, Niel C, Gaspar AM. Hepatitis A virus infection in hepatitis C Brazilian patients. J Infect 2003; 47: 125-128.

10. de Paula VS, Lu L, Niel C, Gaspar AM, Robertson BH. Genetic analysis of hepatitis A virus isolates from Brazil. J Med Virol 2004; 73: 378-383.

11. Fujiwara K, Yokosuka O, Ehata T, Imazeki F, Saisho H. PCR-SSCP analysis of 5'-nontranslated region of hepatitis A viral RNA: comparison with clinicopathological features of hepatitis A. Dig Dis Sci 2000; 45: 2422-2427.

12. Fujiwara K, Yokosuka O, Ehata T, Saisho H, Saotome N, Suzuki K, et al. Association between severity of type $A$ hepatitis and nucleotide variations in the $5^{\prime}$ non-translated region of hepatitis $A$ virus RNA: strains from fulminant hepatitis have fewer nucleotide substitutions. Gut 2002; 51: 82-88.

13. Bower WA, Nainan OV, Han X, Margolis HS. Duration of viremia in hepatitis A virus infection. J Infect Dis 2000; 182: 12-17.
14. Pina S, Buti $M, J$ ardi $R$, Clemente-Casares $P$, J ofre J, Girones R. Genetic analysis of hepatitis $A$ virus strains recovered from the environment and from patients with acute hepatitis. J Gen Virol 2001; 82: 2955-2963.

15. Felsenstein J. Phylogenetic inference package, version 3.5. Seattle: Department of Genetics, University of Washington; 1993.

16. Kumar S, Tamura K, J akobsen IB, Nei M. MEGA2: molecular evolutionary genetics analysis software. Bioinformatics 2001; 17: 12441245.

17. Tanaka J. Hepatitis A shifting epidemiology in Latin America. Vaccine 2000; 18 (Suppl 1): S57-S60.

18. de Almeida LM, Amaku M, Azevedo RS, Cairncross S, Massad E. The intensity of transmission of hepatitis $A$ and heterogeneities in socio-environmental risk factors in $\mathrm{R}$ io de J aneiro, Brazil. Trans $\mathrm{R}$ Soc Trop Med Hyg 2002; 96: 605-610.

19. Lagos R, Potin M, Munoz A, Abrego P, San Martin OS, Ureta AM, et al. Serum antibodies against hepatitis $A$ virus among subjects of middle and low socioeconomic levels in urban area of Santiago, Chile. Rev Med Chil 1999; 127: 429-436.

20. Lopez H, Zitto T, Bare P, Vidal G, Vukasovic J, Gomez R. Prevalence of anti-hepatitis $A$ antibodies in an urban middle class area of Argentina: some associated factors. Int J Infect Dis 2000; 4: 34-37.

21. Fix AD, Martin OS, Gallicchio L, Vial PA, Lagos R. Age-specific prevalence of antibodies to hepatitis $A$ in Santiago, Chile: risk factors and shift in age of infection among children and young adults. Am J Trop Med Hyg 2002; 66: 628-632.

22. de Paula VS, Baptista ML, Lampe E, Niel C, Gaspar AM. Characterization of hepatitis $A$ virus isolates from subgenotypes IA and IB in Rio de J aneiro, Brazil. J Med Virol 2002; 66: 22-27.

23. Diaz BI, Sariol CA, Normann A, Rodriguez L, Flehmig B. Genetic relatedness of Cuban HAV wild-type isolates. J Med Virol 2001; 64: 96-103.

24. Mbayed VA, Sookoian S, Alfonso V, Campos RH. Genetic characterization of hepatitis $A$ virus isolates from Buenos Aires, Argentina. J Med Virol 2002; 68: 168-174.

25. Fujiwara K, Yokosuka O, Imazeki F, Saisho H, Saotome N, Suzuki $\mathrm{K}$, et al. Analysis of the genotype-determining region of hepatitis $\mathrm{A}$ viral RNA in relation to disease severities. Hepatol Res 2003; 25: 124-134.

26. Brown EA, Day SP, J ansen RW, Lemon SM. The 5' nontranslated region of hepatitis $A$ virus RNA: secondary structure and elements required for translation in vitro. J Virol 1991; 65: 5828-5838.

27. Schultz DE, Honda M, Whetter LE, McKnight KL, Lemon SM. Mutations within the $5^{\prime}$ nontranslated RNA of cell culture-adapted hepatitis $A$ virus which enhance cap-independent translation in cultured African green monkey kidney cells. J Virol 1996; 70: 1041-1049. 